\title{
Management of Neonatal Respiratory Distress Syndrome by Indigenous CPAP in a Resource Poor Setting
}

\section{Abstract}

Approximately $25 \%$ of the global neonatal mortality is contributed by India. Many high risk deliveries take place in resource poor settings. A preterm (35 weeks) male newborn delivered in a peripheral private hospital, with respiratory distress syndrome was managed by us using an indigenously developed continuous positive airway pressure (CPAP) circuit. This type of low cost CPAP device may be quite helpful in managing neonatal respiratory ailments in developing nations.

Keywords: Continuous positive airway pressure; Respiratory distress syndrome; Indigenous

Abbreviations: ABG- Arterial blood gas CPAP-Continuous positive airway pressure CRP- $\mathrm{C}$ reactive protein $\mathrm{FiO} 2$ - Fraction of inspired oxygen IV- Intravenous RDSRespiratory distress syndrome SpO2- Oxygen saturation of Hemoglobin

Received: September 11, 2015; Accepted: October 06, 2015; Published: October 25, 2015

\section{Introduction}

Continuous positive airway pressure (CPAP) has been shown to reduce the need for mechanical ventilation. In resource poor settings that are quite prevalent in our country, indigenously developed low cost CPAP devices can be very helpful in lowering the neonatal mortality. We herein describe a preterm newborn with respiratory distress syndrome (RDS) managed with the help of an indigenous nasal CPAP circuit.

\section{Case Report}

A preterm (35 weeks) male newborn was born out of a nonconsanguineous marriage by spontaneous vaginal delivery at a private hospital, with a birth weight of 2500 grams, and cried spontaneously at birth. The mother was a booked case and received regular antenatal care. She did not receive antenatal steroids. The antenatal period was uneventful. The baby had respiratory distress since birth and was kept nil orally on intravenous (IV) fluids, IV antibiotics and oxygen inhalation by head box. The condition of the baby did not improve, and the parents were unable to afford the treatment at the private hospital, so the baby was brought to our hospital at 51 hours of life.

\section{Vishal Pooniya ${ }^{1}$ and NishaPandey ${ }^{2}$}

\author{
1. Department of Pediatrics, King Georges \\ Medical University, Lucknow, India \\ 2. Assistant Professor, Department of \\ Pediatrics, Rohilkhand Medical College, \\ Bareilly, Uttar Pradesh, India
}

\section{Corresponding Author: Vishal Pooniya}

\section{vishalpooniya@gmail.com}

Lecturer, Department of Pediatrics, King Georges' Medical University, Lucknow.

\section{Tel: +966566 625736}

Citation: Pooniya V. Management of Neonatal Respiratory Distress Syndrome by Indigenous CPAP in a Resource Poor Setting. J Pediatr Care. 2015, 1:1. 
saline upto the depth of $5 \mathrm{~cm}$. The other cut end of the tube was sealed with a tape to prevent leakage. The baby was kept nil orally, on IV fluids, IV antibiotics (cefotaxime $150 \mathrm{mg} / \mathrm{kg} /$ day and amikacin $15 \mathrm{mg} / \mathrm{kg} /$ day). He maintained an $\mathrm{S}_{\mathrm{p}} \mathrm{O}_{2}$ of $95 \%$.

His respiratory distress gradually decreased, $\mathrm{FiO}_{2}$ was gradually brought down to 0.3 . After 18 hours, his respiratory rate decreased to $70 /$ minute, and he was maintaining a $\mathrm{SpO}_{2}$ of $98 \%$.

CPAP was removed at this point and he was put on oxygen by hood at 5 liters/minute. By 81 hrs of life, his respiratory distress had settled, and activity and tone improved. Oxygen was removed and he maintained an SpO2 of $\geq 95 \%$ on room air. Breast feeds were started which the baby accepted well. As there was no clinical or laboratory evidence of sepsis, antibiotics were stopped after 72 hours. The baby was discharged on day 5 of life on exclusive breast feeding.

\section{Discussion}

The neonatal mortality in India is still amongst the highest in the world. Almost a quarter of the burden of neonatal mortality is shared by India. Of the 26 million babies born annually in our country, $65 \%$ are delivered at home and more than half by semiskilled and unskilled Traditional Birth Attendants [1]. Most of the deliveries in our country still take place in ill-equipped centers and facilities for neonatal transport are almost non-existent. Hence, there is a need for low cost methods for providing care to the high risk newborns in peripheral health care Centre's.

Nasal CPAP is widely used for a variety of neonatal respiratory conditions all over the world. It is established as an effective method of preventing extubation failure, is used in the management of apnoea of prematurity, and is increasingly seen as an alternative to intubation and ventilation for the treatment of RDS [2,3].

In our case, the baby required ventilator support, but our hospital had only two mechanical ventilators and both were occupied at that moment. Hence we prepared an indigenous bubble CPAP circuit to salvage the baby. A diagram of our circuit is shown in Figure 1. The bubble CPAP circuit that we utilized was first described by Kaur et al. [4], which can deliver $21 \%$ to $98 \%$ of oxygen. We did not have the humidifier, so we provided unhumidified oxygen to the baby.

Furthermore, we could not perform ABG due to unavailability. Nevertheless, with the help of this low cost indigenous method, we were able to salvage this baby, which could probably otherwise have deteriorated.

This case highlights the possibility of wider application of such indigenous techniques in resource poor settings in the developing nations, which may contribute in lowering the neonatal mortality, but further studies on an adequate sample size are required before making any recommendations.

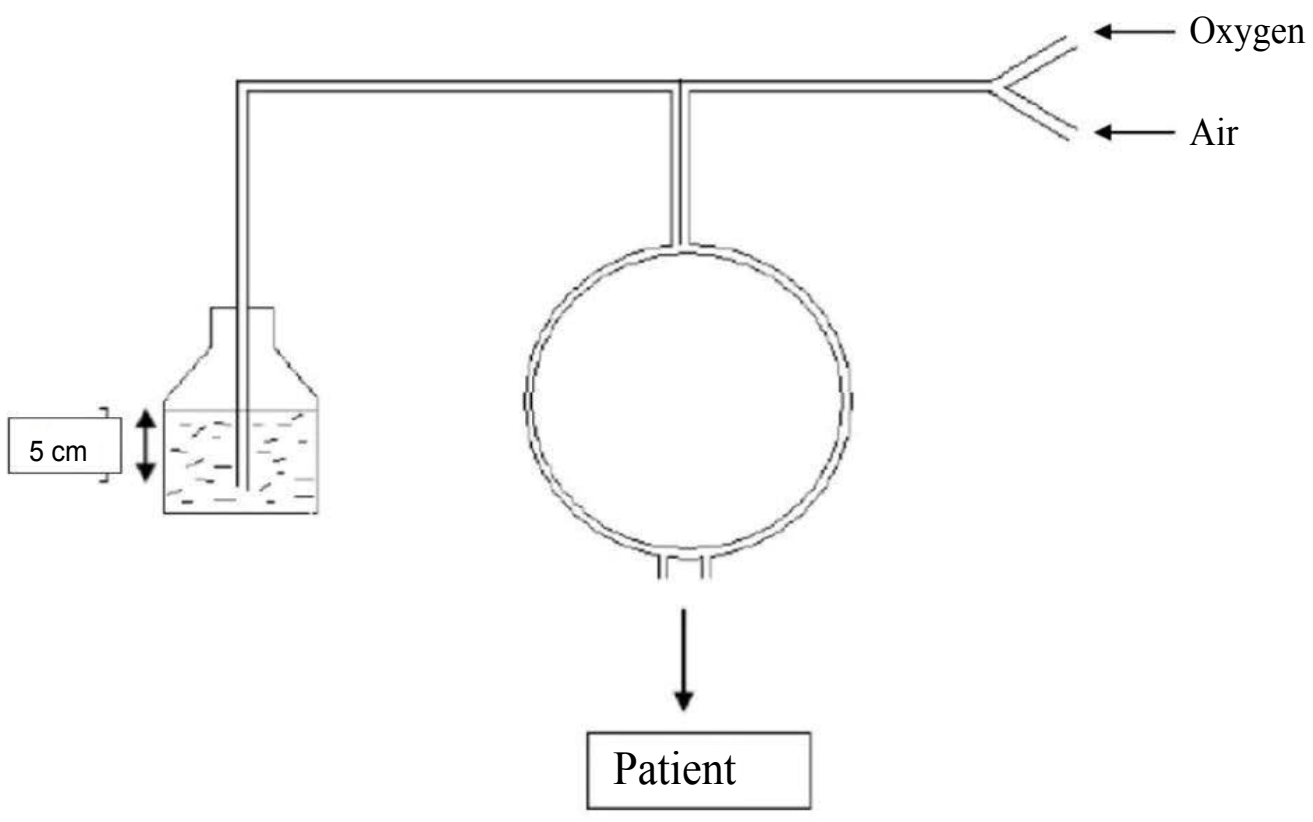

Figure 1 A diagram showing the outline of the indigenously prepared bubble CPAP circuit. 


\section{References}

1 Nair MKC, Jana AK, Niswade AK (2005) Neonatal survival and beyond. Indian Pediatr. 42: 985-988.

2 Davis PG, Henderson-Smart DJ (2002) Nasal continuous positive airway pressure immediately after extubation for preventing morbidity in preterm infants. The Cochrane Library, Issue 1. Oxford: Update Software.
3 De Paoli AG, Morley C, Davis PG (2003) Nasal CPAP for neonates: what do we know in 2003? Arch Dis Child Fetal Neonatal Ed 2003; 88: F168-F172.

4 Kaur C, Sema A, Beri RS, Puliyel JM (2008) A simple circuit to deliver bubbling CPAP. Indian Pediatr. 45: 312-314. 